\title{
Editorial \\ Echocardiography in acute respiratory distress syndrome: a promising clinical tool
}

Volume 4 Issue 3 - 2016

\section{Editorial}

In Acute Respiratory Syndrome (ARDS) treatment of lung injury is based mainly on protective ventilation, but pulmonary vascular injury associated with this disease condition is being considered as a therapeutic target, together with its effects on the right ventricle (RV) and on systemic hemodynamics. In this context, bedside use of Doppler echocardiography is being featured as a promising, clinically useful tool ${ }^{1}$ in assessing the pulmonary circulation and right ventricular function (as well as biventricular function) in ARDS patients. ${ }^{2-4}$ Since the first report in 1985 by Jardin et al. ${ }^{5}$ describing the right (RV) and left ventricle (LV) functions with echocardiography in a small subset of patients with acute respiratory failure, an increasing number of papers have been published on this topic, but the available evidence mainly concerns the prevalence and the prognostic impact of acute corpulmonale (ACP) in ARDS. ${ }^{2,4,6}$

Briefly, in the era of protective ventilation, ACP occurs in the 20$25 \%$ of ARDS patients and its development seems to be especially related to plateau pressure, driving pressure and $\mathrm{pCO}_{2}$ [4]. The presence of ACP may cause or precipitate circulatory failure and it seems to have an impact on prognosis since it resulted an independent risk factor for 28-day mortality in moderate-to-severe ARDS patients. ${ }^{7}$ Based on the echocardiographic findings on ACP in ARDS patients and its clinical meaning, it has been proposed an approach to protect the right ventricle by setting/adapting the ventilatory strategy in presence of echocardiographic finding of RV overload. ${ }^{4,-15}$ Though this "protective RV approach" has to be validated in a randomized controlled trial, it has an indubitable clinical relevance since it aims to protect both the lung and the ventricle by a single-patient tailored strategy. In presence of ACP the adaptation of the ventilatory settings to RV function may consist in decreasing the plateau pressure (below 27 to $28 \mathrm{~cm}$ of $\mathrm{H} 2 \mathrm{O}$ ), limiting the PEEP, avoiding intrinsic PEEP, and controlling hypercapnia. In this setting in ARDS patients, it is now recommended to perform at least one echocardiographic examination per day during the first 3 days to evaluate RV function and to adapt the ventilator.

New lines of evidence strongly suggest a potential clinical role of echocardiography in ARDS patients since the early phase of the disease. ${ }^{16}$ Three elements, which can be all investigated by echocardiography, characterize the pulmonary vascular alterations and its effects on the right ventricle and systemic circulation in ARDS: a) pulmonary systolic arterial hypertension (sPAP); b) RV dimension and function; c) septal dyskinesis. The clinical significance (that is prognostic impact and/or potential therapeutic target) of each of these three elements has not yet been elucidated. Boissier et al. ${ }^{7}$ observed that moderate $\mathrm{RV}$ dilation (defined as $\mathrm{RV} / \mathrm{LD}$ end diastolic area ratio $>0.6$ and $<1$ ) was detectable in the $49 \%$ of patients without ACP, thus suggesting that RV dilation may precede ACP development and a progressive increase in mortality was observed with increase in pulmonary dysfunction severity. In a small subset of 21 patients with refractory ARDS treated with Veno-Venous Extracorporeal

\author{
Chiara Lazzeri,' Adriano Peris² \\ 'Intensive Care Unit of Heart and Vessels Department, Italy \\ ${ }^{2}$ Intensive Care Unit and Regional ECMO Referral center, \\ Azienda Ospedaliero-Universitaria Careggi, Italy
}

Correspondence: Chiara Lazzeri, Intensive Care Unit of Heart and Vessels Department, Italy, Email lazzeric@libero.it

Received: January 23, 2016 | Published: February 02, 2016

Membrane Oxygenation, ${ }^{17,18}$ the prevalence of acute cor pulmonale was low (9.5\%) but a lower incidence of RV dysfunction (as indicated by Tricuspid Anular Plane Excursion), lower peak systolic pulmonary arterial pressures and higher values of left ventricle ejection fraction were found in survivors in comparison with dead patients. In moderate-to-severe ARDS, ${ }^{19}$ serial troponin I assessment together with echocardiography evaluation helped to identify a subgroup at higher risk for in-ICU death since systolic pulmonary arterial pressure (together with troponin $\mathrm{I}$ and $\mathrm{pCO}_{2}$ ) were independent predictors of early mortality.

Overall, according to the existing evidence, echocardiography (transthoracic and transesophageal) has a growing role in the management ARDS patients mainly because of the strict interactions between the lung (and ventilation) and the right ventricle and pulmonary circulation. There may be a continuum of alterations in RV size and function and pulmonary circulation which may end in the development of ACP, probably paralleling ARDS disease severity.

However, several questions still remain open and intriguing for intensivists taking into account that the clinical interpretation of echocardiographic findings, though challenging (due to the numerous potential causal mechanisms ranging from disease severity to ventilatory strategy) may have impact on the therapeutic regimen (i.e. use of inotropic durgs, volemia and/or change in ventilatory setting). Therefore there is the clinical need to address future research to elucidate the role of echocardiography in ARDS as a tool for risk stratification and/or targeting therapy.

\section{References}

1. Mayo P, Mekontso Dessap A, et al. Myths about critical care echocardiography: the ten false beliefs that intensivists should understand. Intensive Care Med. 2015;41(6):1103-1106.

2. Chiumello D, Pesenti A. The monitoring of acute cor pulmonale is still necessary in "Berlin" ARDS patients. Intensive Care Med. 2013;39(10):1864-1866. 
3. Khrishnan S, Schmidt GA. Acute right ventricular dysfunction. A realtime management with echocardiography. Chest. 2015;147(3):835-846.

4. Repessé X, Charron C, Vieillard-Baron A. Acute Cor Pulmonale in ARDS: Rationale for Protecting the Right Ventricle. Chest. 2015;147(1):259-265.

5. Jardin F, Gueret P, Dubourg O, et al. Two-dimensional echocardiographic evaluation of right ventricular size and contractility in acute respiratory failure. Crit Care Med. 1985;13(11):952-956.

6. Vieillard-Baron A. Assessment of right ventricular function. Curr Opin Crit Care. 2009;15:254-260.

7. Boissier F, Katsahian S, Razazi K, et al. Prevalence and prognosis of cor pulmonale during protective ventilation for acute respiratory distress syndrome. Intensive Care Med. 2013;39(10):1725-1733.

8. Jardin F, Dubourg O, Bourdarias JP. Echocardiographic pattern of acute cor pulmonale. Chest. 1997;111(1):209-217.

9. Legras A, Caille A, Begot E, et al. Acute respiratory distress syndrome (ARDS)-associated acute cor pulmonale and patent foramen ovale: a multicenter noninvasive hemodynamic study. Critical Care. 2015;19:174.

10. Mekontso DA, Boissier F, Leon R, et al. Prevalence and prognosis of shunting across patent foramen ovale during acute respiratory distress syndrome. Crit Care Med. 2010;38(9):1786-1792.

11. Mekontso DA Charron C, Devaquet J, et al. Impact of acute hypercapnia and augmented postivie end-expiratory pressure on right ventricle function in severe acute respiratory distress syndrome. Intensive Care Med. 2009;35(11):1850-1858.
12. Vieillard-Baron A, Schmitt JM, Augarde R, et al. Acute cor pulmonale in acute respiratory distress syndrome submitted to protective ventilation: incidence, clinical implications, and prognosis. Crit Care Med. 2001;29(8):1551-1555.

13. Vieillard-Baron A, Charron C, Caille V, et al. Prone positioning uploads the right ventricle in severe ARDS. Chest. 2007;132(5):1440-1446.

14. Vieillard-Baron A, Price LC, Matthay MA. Acute cor pulmonale in ARDS. Intensive Care Med. 2013;39(10):1836-1838.

15. Lhéritier G, Legras A, Caille A, et al. Prevalence and prognostic value of acute cor pulmonale and patent foramen ovale in ventilated patients with early acute respiratory distress syndrome: a multicenter study. Intensive Care Med. 2013;39(10):1734-1742

16. Lazzeri C, Cianchi G, Bonizzoli $\mathrm{M}$, et al. The potential role and limitations of echocardiography in acute respiratory distress syndrome. Ther Adv Respir Dis pii: 1753465815621251.

17. Lazzeri C, Cianchi G, Bonizzoli M, et al. Pulmonary vascular dysfunction in refractory acute respiratory distress syndrome before veno-venous extracorporeal membrane oxygenation. Acta Anaesthesiol Scand doi: 10.1111/aas.12643.

18. Lazzeri C, Bonizzoli M, Cozzolino C, et al. Serial Measurements of Troponin and Echocardiography in Patients with Moderate-to-Severe Acute Respiratory Distress Syndrome. Journal of Critical Care DOI: http://dx.doi.org/10.1016/j.jcrc.2016.01.004. 